\title{
Reconstructing the history of a fragmented and heavily exploited red deer population using ancient and contemporary DNA
}

\author{
Jørgen Rosvold ${ }^{1 *}$, Knut H Røed ${ }^{2}$, Anne Karin Hufthammer ${ }^{3}$, Reidar Andersen ${ }^{4}$ and Hans K Stenøien ${ }^{1}$
}

\begin{abstract}
Background: Red deer (Cervus elaphus) have been an important human resource for millennia, experiencing intensive human influence through habitat alterations, hunting and translocation of animals. In this study we investigate a time series of ancient and contemporary DNA from Norwegian red deer spanning about 7,000 years. Our main aim was to investigate how increasing agricultural land use, hunting pressure and possibly human mediated translocation of animals have affected the genetic diversity on a long-term scale.
\end{abstract}

Results: We obtained mtDNA (D-loop) sequences from 73 ancient specimens. These show higher genetic diversity in ancient compared to extant samples, with the highest diversity preceding the onset of agricultural intensification in the Early Iron Age. Using standard diversity indices, Bayesian skyline plot and approximate Bayesian computation, we detected a population reduction which was more prolonged than, but not as severe as, historic documents indicate. There are signs of substantial changes in haplotype frequencies primarily due to loss of haplotypes through genetic drift. There is no indication of human mediated translocations into the Norwegian population. All the Norwegian sequences show a western European origin, from which the Norwegian lineage diverged approximately 15,000 years ago.

Conclusions: Our results provide direct insight into the effects of increasing habitat fragmentation and human hunting pressure on genetic diversity and structure of red deer populations. They also shed light on the northward post-glacial colonisation process of red deer in Europe and suggest increased precision in inferring past demographic events when including both ancient and contemporary DNA.

Keywords: Ancient DNA, Habitat fragmentation, Harvesting, Mitochondrial DNA, Genetic diversity, Translocation, Cervus elaphus

\section{Background}

Humans have a major impact on the evolution and survival of other life forms [1]. Our activities may modify the genetic diversity and structure of other species through e.g. heavy harvesting, habitat fragmentation and translocation of populations [2,3], often reducing their fitness and future adaptive potential $[4,5]$. Red deer (Cervus elaphus) are one of the most common and widespread of European ungulates today [6]. However, due to heavy hunting and habitat alterations, many populations

\footnotetext{
* Correspondence: jorgen.rosvold@ntnu.no

'Section of Natural History, Museum of Natural History and Archaeology, Norwegian University of Science and Technology, N-7491 Trondheim, Norway

Full list of author information is available at the end of the article
}

were severely reduced in numbers in previous centuries. Several populations were driven to extinction or confined to scattered and isolated refugia from which they have later expanded [6]. Even today the widespread distribution is often patchy and fragmented, a trend that is increasing in some areas as a result of habitat loss and overhunting [7]. Red deer have also been subjected to poorly documented human mediated translocations of animals, often over large distances, leading to mixing with or substitution of the indigenous population [6]. Such translocations could potentially disrupt long-term local adaptations of populations [8].

Norwegian red deer represents the end point of the northward post-glacial colonisation of the western European red deer lineage [9] and relatively low genetic

\section{Biomed Central}


diversity has been found in contemporary populations $[10,11]$. Traditionally it was described as a separate subspecies (C. e. atlanticus), but this is not supported in more recent analyses based on skull morphology [12] or molecular phylogenetics [13,14]. Norwegian deer are, nevertheless, differentiated both morphologically and genetically from Swedish and Danish populations and seem more closely related to Scottish red deer $[10,15]$. This differentiation among Scandinavian red deer has been explained either by post-glacial separation and adaptations to different environments, or alternatively, that they originate from different source populations $[15,16]$. Explanations for the latter hypothesis suggest two waves of post-glacial immigration to northern Europe, with the first wave dominating the Norwegian population, and a later human mediated translocation of animals possibly by Vikings $[10,15,17]$. There are numerous findings of prehistoric red deer bones in Norway and, according to older documents e.g. [18], they were widespread and numerous in the $16^{\text {th }}$ century AD before rapidly declining in numbers, allegedly as an effect of increased hunting pressure and wolf predation. A similar decline was reported in Sweden [19] and in the $19^{\text {th }}$ century the Scandinavian red deer had been reduced to a few isolated locations, estimated to consist of only a few hundred animals in total [20]. Following strict hunting regulations, an almost exponential growth took place during the last century and the current estimated Norwegian census size is well above 100,000 individuals, mainly distributed along the west coast of the Scandes mountains [17].

In this study we analyse contemporary and ancient genetic diversity in Norwegian red deer in a time-series of mitochondrial DNA (mtDNA) sequences spanning the last 7,000 years. Our aim is to estimate the timing, pattern and magnitude of the historic population decline using different methods to detect past demographic changes. In addition, we explore the relationship to other European populations and the possibility of human translocation of red deer into Norway. We

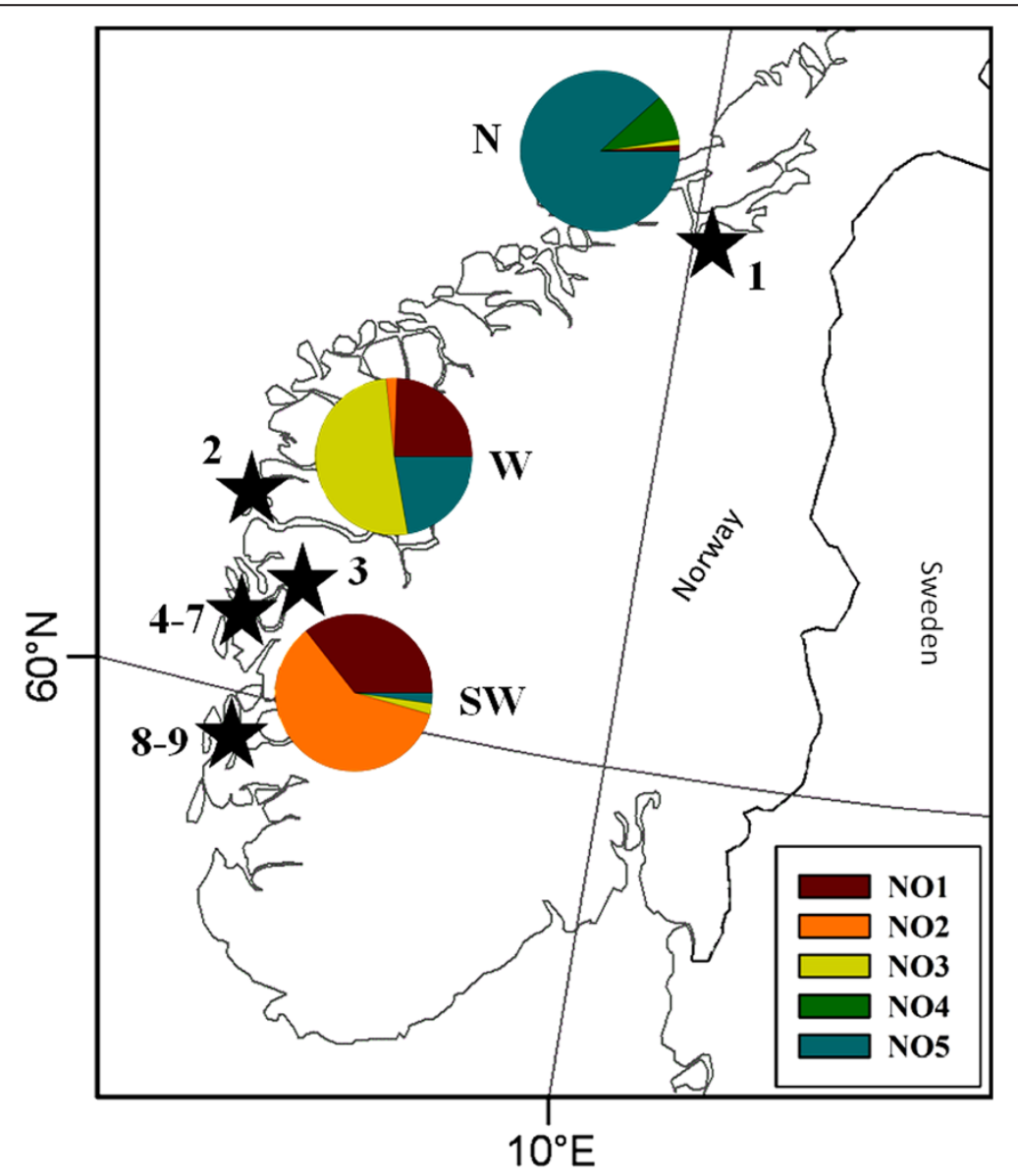

Figure 1 Study sites and distribution of contemporary red deer mtDNA haplotypes in Norway. Stars mark the distribution of archaeological locations with samples used in the aDNA analyses. 1-Erkebispegården, 2-Grønehelleren, 3-Skipshelleren, 4-Dreggsalmenningen, 5-Rosenkrantzgate, 6-Grimstadneset, 7-Ruskeneset, 8-Rundøyno, 9-Geitalemen. Pie charts show the relative distribution of haplotypes (NO1-NO5) in contemporary red deer in three geographic regions: SW, W and N. 
analyse contemporary DNA together with ancient DNA (aDNA) using Bayesian methods and investigate whether including aDNA significantly changes the outcome of our analyses. Our results provide direct insights into the effects of increasing agricultural land use and human hunting pressure on genetic diversity and structure on a long timescale, and shed light on the northward postglacial colonization process of red deer in Europe.

\section{Methods}

\section{Sampling and dating}

A total of 142 Holocene samples of subfossil red deer skeletal remains were collected from nine archaeological sites in Norway for aDNA analysis of the mtDNA control region (D-loop) (Figure 1 and Table 1). Samples were ${ }^{14} \mathrm{C}$ dated when originating from poorly dated sites or with an insecure stratigraphy (Additional file 1: Table S1). ${ }^{14} \mathrm{C}$ dates were calibrated using CALIB 5.0.1 [21] with Incal04 calibration curve [22] and all dates reported in the text are in calendar years before present (yr BP). The age of the samples range from the Mesolithic to the Late Middle Ages (c. 7,000-500 yr BP) and all samples were collected from the University Museum of Bergen. Data on contemporary Norwegian and European mtDNA diversity were compiled from the literature ([14,23-29], Haanes et al. unpublished results), excluding sequences from populations described by authors as translocated by humans during the last centuries. Nine new sequences from contemporary Norwegian animals were also included (see Additional file 1: Table S2 for overview of contemporary samples).

\section{DNA extraction, amplification and sequencing}

We drilled out 30-50 mg of powder from the samples using a Dremel multitool on slow speed. DNA was extracted using Qiagen DNeasy Tissue Kit by adding to the samples $300 \mu \mathrm{l}$ Buffer ATL, $200 \mu \mathrm{l} 1 \mathrm{M}$ EDTA (pH 8 ) and $35 \mu \mathrm{l}$ proteinase $\mathrm{K}$, incubating in a thermomixer at $55^{\circ} \mathrm{C}$ over night. We used $450 \mu \mathrm{l}$ of this in extractions following the Qiagen protocol. Polymerase chain reaction (PCR) amplifications of a $327 \mathrm{bp}$ long sequence were performed using two pairs of overlapping primers which were first tested using contemporary samples of red deer:

I. (Ce116F) 5'-CCACCAACCACACAACAAAA-3' with (Ce343R) 5'-GATCTAGGGGACGGGATACG3';

II. (CeCRF251) 5' -TGCCCCATGCATATAAGCATG3' with (CeCRR519) 5'-TAGGTGAGATGGCCC TGAAAAAAG-3'.

Amplifications were performed in $25 \mu \mathrm{l}$ reaction mixtures containing 4-8 $\mu \mathrm{l}$ DNA extract, $0.625 \mathrm{U}$ of $P f u-$ Turbo Hotstart DNA Polymerase (Stratagene), $2.5 \mu \mathrm{l} 10 \mathrm{x}$ Pfu buffer, 12.5 pmol of each primer, $2.5 \mu \mathrm{g}$ bovine serum albumin (Sigma) and $200 \mu \mathrm{M}$ of each dNTP. The PCR profile was 2 min denaturation at $95^{\circ} \mathrm{C}$ followed by 46 cycles of $30 \mathrm{~s}$ denaturation at $95^{\circ} \mathrm{C}, 30 \mathrm{~s}$ annealing at $72^{\circ} \mathrm{C}, 60 \mathrm{~s}$ of extension at $72^{\circ} \mathrm{C}$, and a final extension step of $10 \mathrm{~min}$ at $72^{\circ} \mathrm{C}$. Amplified PCR products were cleaned using ExoSAP-IT (USB). Sequencing of both strands was performed using BigDye terminator cycle sequencing kit v.1.1 on an ABI 3100 genetic analyser. Sequences were inspected and aligned by eye with aid of MEGA v.4 [30].

\section{Authentication}

Several precautions were taken to ensure amplification of authentic DNA from the ancient samples [31]. All equipment and working surfaces were cleaned using sodium hypochlorite, ethanol or UV-light. Drilling and extraction were done in designated labs physically separated from post-PCR laboratories, and where no previous work on red deer had been done before. Lab coats and breathing masks were used, gloves were changed frequently and drill bits were changed for each sample. Samples were mechanically cleaned and the outer surface was removed before drilling out the powder. Blank extraction and PCR controls were used in each reaction and only DNA sequences which could be replicated from at least two independent amplifications of

Table 1 Archaeological sites from which samples were taken for aDNA analysis

\begin{tabular}{|c|c|c|c|c|c|c|}
\hline Site \# & Site name & County & Municipality & c. Age (BP) & \# sampl. & Success rate \\
\hline 1 & Erkebispegården & Sør-Trøndelag & Trondheim & 500 & 5 & $60 \%$ \\
\hline 2 & Grønehelleren & Sogn \& Fjordane & Solund & $4000-1400$ & 21 & $48 \%$ \\
\hline 3 & Skipshelleren & Hordaland & Vaksdal & $7500-1800$ & 68 & $51 \%$ \\
\hline 4 & Dreggsalmenningen & Hordaland & Bergen & 500 & 2 & $50 \%$ \\
\hline 5 & Rosenkrantzgate & Hordaland & Bergen & 500 & 20 & $95 \%$ \\
\hline 6 & Grimstadneset & Hordaland & Bergen & 2000 & 7 & $29 \%$ \\
\hline 7 & Ruskeneset & Hordaland & Bergen & $4000-2000$ & 6 & $0 \%$ \\
\hline 8 & Rundøyno & Hordaland & Bømlo & $4000-2500$ & 7 & $29 \%$ \\
\hline 9 & Geitalemen & Hordaland & Sveio & 3800 & 5 & $20 \%$ \\
\hline
\end{tabular}


each primer pair were used in the subsequent analyses. In addition, the primer pairs were overlapping for $84 \mathrm{bp}$ of the target sequence yielding four replicates or more of the most variable region, thereby ensuring that nuclear copies (NUMTS) could be avoided [32]. We cloned and sequenced a sample of each new haplotype found, using 10 clones from each sample. Cloning was performed according to the Topo TA Cloning protocols (Invitrogen) with PCR-products extracted from gel using the MinElute Gel Extraction Kit protocol (Invitrogen).

\section{Analysing genetic diversity and population structure}

A previous analysis using microsatellites found a strong genetic differentiation of the present Norwegian populations north and south of the Sognefjord area [33]. We therefore pooled our contemporary data into three geographic regions along a north-south transect: the northern part of the distribution, including Møre \& Romsdal and Trøndelag counties (N); the Sognefjord area (W); and the southwest, including Rogaland and Hordaland counties (SW). We tested for population structure between the three areas by calculating F-statistics using only haplotype frequencies $\left(\mathrm{F}_{\mathrm{ST}}\right)$ [34] and $\Phi_{\mathrm{ST}}$ which also accounts for genetic distance between haplotypes [35]. Significance values were obtained after 10,000 permutations using the software Arlequin v. 3.1 [36].

Estimates may become biased when analysing populations with a pronounced population structure [37-49], and to better meet assumptions of panmixia we excluded "site 1" from the ancient samples and the $\mathrm{N}$ region from the contemporary data set focusing only on "western Norway" on subsequent analyses of genetic diversity through time. The data was divided into four time periods which were treated as separate "populations" in the analyses: c. 7,000-3,500 yr BP (midHolocene); c. 2,500-2,000 yr BP (representing the period before any suspected bottleneck and translocations); c. 1,500-500 yr BP (a period including the human Migration Period, the Viking Age and the Middle Ages); and the present. We calculated standard genetic diversity indices, $\theta_{\mathrm{k}}$ [40], Tajima's $\mathrm{D}$ [41] and Fu's $\mathrm{F}_{\mathrm{s}}$ [42] on both the present and ancient data sets using the software Arlequin.

\section{Bayesian skyline plot}

A Bayesian Skyline Plot (BSP) [43] implemented in BEAST v.1.6.1 [44] was used to explore past demographic changes in the red deer population. This approach was also used to obtain a direct estimate of substitution rate by using the age of individual sequences as calibrating information [45]. Sequence ages were rounded to the nearest $500 \mathrm{yr}$ BP as most samples were not directly dated but were obtained from well dated stratigraphic layers with a certain age range (Additional file 1: Table S3). Substitution model was selected using the Aikake information criterion in jModelTest v. 0.1.1 [46,47], suggesting that the HKY model had the best fit to the data set [48]. Both a strict and a relaxed molecular clock were applied; the results were similar and a strict clock was used for the final runs. We summarized the lineage coalescent events into ten groups to smooth the estimates over time. MCMC was run for 100 mill iterations, sampling every 10,000 th step and with a $10 \%$ burn-in. To estimate model parameters we ran two independent runs which were combined and inspected using TRACER v.1.5 [49]. To evaluate support for the BSP model we also did a run using a constant size coalescent tree prior instead of the BSP, comparing the different runs using Bayes factors [50].

\section{Approximate Bayesian computation analysis}

We estimated historical parameters for the Norwegian red deer; i.e. time since immigration(s), effective population size through time, and the genetic effect of bottleneck(s) in modern times; in a coalescence framework using approximate Bayesian computation (ABC) [51] and the DIY-ABC software ver. 1.0.4.37 [52]. Based on the results from the above analyses we explored two different scenarios with either one (scenario 1) or two colonisation events (scenario 2), with the second being a late translocation event possibly from the British Isles during the Viking ages (Figure 2).

In two initial runs we compared the effects of using larger effective population size of females than of males (with a ratio of 0.1), compared to a scenario where they were equal, using similar parameter settings and prior ranges as described below. The results did not differ between the two approaches (results not shown), and we therefore did a full scale analysis assuming an equal sex ratio. We modelled two populations: Norway and Europe, with current effective population sizes $N_{\text {NOR }}$ and $N_{\text {EUR }}$ respectively. To represent the European diversity, one haplotype from 15 different western European populations were randomly picked, 13 from Skog et al. [14], one from Nielsen et al. [27] and one from McDevitt et al. [24]. Such sampling should yield properties approximating those of a random mating population [53,54]. We used the same time periods as described above to represent a serial sampling of the population at four time points $\left(t_{0}-t_{3}\right)$, with $t_{0}$ representing the contemporary sample and $t_{3}$ the oldest of the ancient samples (Figure 2). In order to convert time estimates to years instead of generations, we assumed a generation time of four years in female red deer [25]. In scenario 1, the Norwegian population went through a population bottleneck starting at $t_{\mathrm{BS}}$ and ending at $t_{\mathrm{BE}}$ years back in time, where the effective population size of the Norwegian 


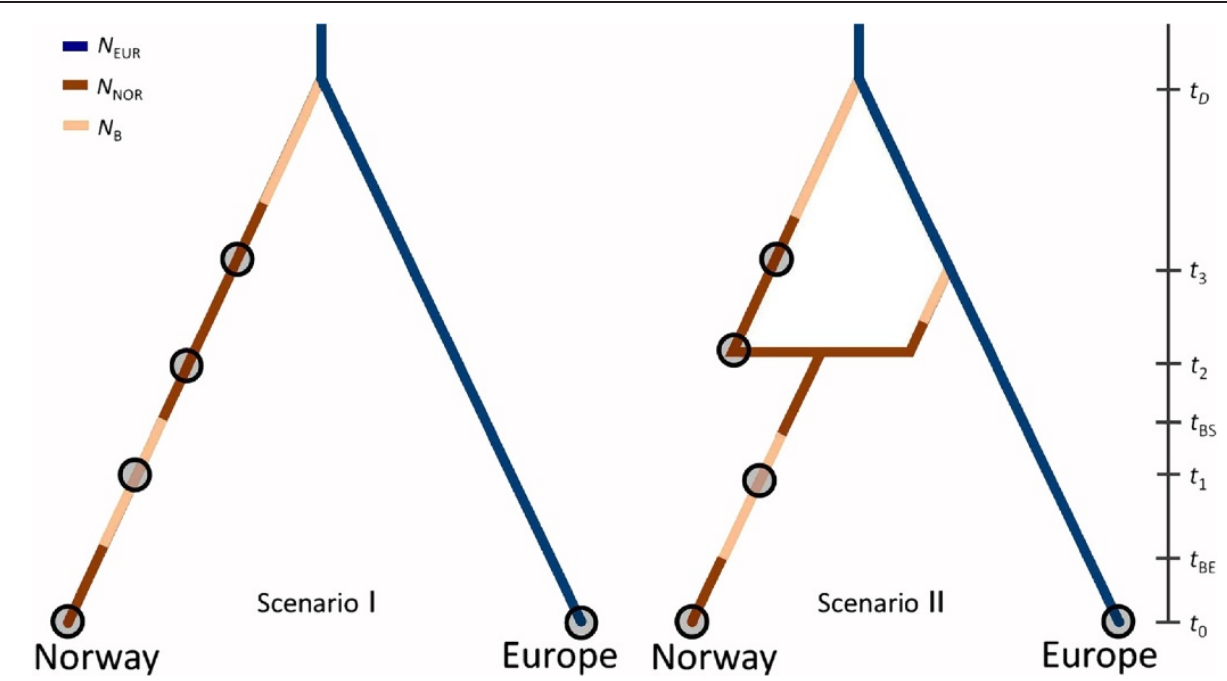

Figure 2 Overview of the scenarios for the $A B C$ analyses. The scenarios depict one or two colonization events of red deer to Norway and estimated population sizes shown in different colours. $t_{0}-t_{3}$ indicate DNA sampling points in time and are marked by circles. Note that we allow the sampling at $t_{2}$ in scenario II to occur either before or after the admixture event. $t_{D}$ denotes the divergence time of the Norwegian population, while $t_{B S}$ and $t_{B E}$ marks the start and end of the estimated population bottleneck respectively.

population is $N_{\mathrm{B}}$. At time $t_{1}$, which we allow to occur either within or before the bottleneck period (i.e. we do not a priori determine the relative size of $t_{\mathrm{BS}}$ and $t_{1}$ ), the Norwegian population is sampled, and prior range for $t_{1}$ is set to between 500 and 1,700 yr BP. The sampling at year $t_{2}$ and year $t_{3}$ is assumed to happen before $t_{\mathrm{BS}}$, i.e., in a period with effective size $N_{\mathrm{NOR}}$, with prior ranges $2,000-2,500 \mathrm{yr}$ BP for $t_{2}$ and 3,500-7,000 yr BP for $t_{3}$. In the period between $t_{\mathrm{D}}-x$ and $t_{\mathrm{D}}$ the Norwegian population experienced a founder event as a result of the colonisation of Norway, with $t_{\mathrm{D}}$ marking the time of divergence from the European population. In scenario 2 we assumed a similar history as in scenario 1, except that there was an immigration and admixture event from the European population before $t_{\mathrm{BS}}$ and either before or after the sampling at $t_{2}$. The second immigrated population underwent a bottleneck for a total of $x$ years and has an effective size $N_{\mathrm{NOR}}$ at the time of admixture. A fraction $r$ of the original Norwegian population and a fraction $1-r$ of the second immigration contribute to the admixed present day population.

We assumed no migration between populations after divergence, implying that the divergence time estimates are to be treated as minimum estimates. Prior ranges of the effective population size were set to $1,000-100,000$ for $N_{\mathrm{NOR}}$ and $N_{\mathrm{B}}$, and 1,000 - 1,000,000 for $N_{\mathrm{EUR}}$. Based on the results from the Bayesian skyline plot (see below) we assumed that a putative bottleneck started between $500-2,500$ yr BP and ended $1-500$ years ago. The postglacial divergence of the Norwegian and European populations was set to occur between 9,000 and $20,000 \mathrm{yr}$ BP. In scenario 2 the second divergence of the
Norwegian population from the European was set to occur between 3,500 and 20,000 yr BP, with an original bottleneck lasting between 1 and 500 years. The admixture between the first and the second Norwegian populations occurred between 500 and 2,500 yr BP, before or after the sampling at $t_{2}$.

Mutation rates were treated as nuisance parameters, and we assumed a Kimura 2-parameter model [55] with prior mutation rate estimate range obtained from the BEAST analyses (see below). Summary statistics were computed for each sample in each simulation, i.e. number of haplotypes, Tajima's D, number of private segregating sites and average number of pairwise differences for each pair of populations sampled together. Each scenario was tested using 1 mill simulations, i.e., 2 mill simulations in total for the testing of scenarios 1 and 2 .

The scenarios were compared using two approaches; one by directly comparing the summary statistics with the observed diversity in the data set and counting the frequency of the various scenarios among the most similar simulated datasets [56,57], and one by doing a logistic regression of each scenario probability for the most similar simulated data sets on the deviations between simulated and observed summary statistics $[58,59]$. In the direct comparisons approach the 500 simulated data closest to the observed values were used, while in the regression approach we used $1 \%$ of the simulated data closest to the observed data set. Confidence in scenario choice was evaluated by choosing scenario 1 as the true scenario and then simulating 500 data sets using this scenario and parameter values drawn randomly from the 
prior distributions, and then doing the same for scenario 2 . The proportion of times the most likely scenario did not have the highest posterior probability when it was the true scenario was used as an estimate of type I error. The number of times the most likely scenario had the highest probability when it was not the true scenario was used as an estimate of type II error. Parameters were estimated for the most likely scenario using the 1\% simulations for a given scenario most similar to the observed data set for the summary statistics employed. In order to evaluate the performance of the estimation procedure, we generated pseudo-observed data sets with known parameter values drawn from the posterior distribution given the most likely scenario. The mean relative bias (MRB), $\frac{1}{n} \sum_{i=1}^{n} \frac{e_{i}-v_{i}}{v_{i}}$, was estimated, where $e_{i}$ is the $i$ 'th estimate of the pseudo-generated true value $v$, and averaged over the $\mathrm{n}=500$ data sets.

In order to study the impact of including aDNA samples, we chose the scenario with the highest estimated posterior probability (scenario 1, see below), and re-ran the $\mathrm{ABC}$ analyses using only extant DNA samples. In these simulations we assumed a similar history as in scenario 1 above, except that we had no aDNA samples, i.e. $t_{1}-t_{3}$ were not included.

\section{Relationships between haplotypes}

Relationships between haplotypes were investigated both on a national (Norwegian) and western European level using three different phylogenetic network methods: median-joining in Network v.4.6.0.0 [60], statistical parsimony in TCS v.1.21 [61] and NeighborNet in SplitsTree4 v.4.11.3 [62].

\section{Results}

\section{Amplification success and authentication of} ancient samples

We successfully sequenced $73(51.4 \%)$ of the ancient samples from which we identified 10 haplotypes: NO1 NO10 [GenBank: JX861260-JX861269] (Table 1; Additional file 1: Table S3). A BLAST search [63] revealed that three haplotypes (NO8 - NO10) were novel. The three network methods yielded the same relationship between the ten Norwegian haplotypes showing a close relationship and a star-like pattern with $\mathrm{NO} 4$ as the central type (Figure 3 ).

None of the negative controls contained red deer DNA, but some samples showed contamination from cattle (Bos taurus) when using primer pair II, a common problem in aDNA studies [64]. All clones produced identical sequences, except four clones in sample A1348 (NO9) which showed a G-A transition, typical of postmortem DNA decay [65]. This was only expressed in the clones and was distinct from the segregating site that distinguished this haplotype. Most of the variable sites were also within the overlapping part of the two primer pairs and the independent replicates were always identical. We therefore have good reason to believe that all resulting sequences are authentic.

\section{Present population structure and diversity}

176 control region sequences $\left(\mathrm{n}_{\mathrm{N}}=86 ; \mathrm{n}_{\mathrm{W}}=45 ; \mathrm{n}_{\mathrm{SW}}=\right.$ 45) were gathered from the extant Norwegian red deer distribution. From these we identified five different haplotypes (NO1 - NO5), identical to five of the ancient samples. The frequency and distribution of the haplotypes differed strongly among the three regions (Figure 1), with a significant genetic structure (global

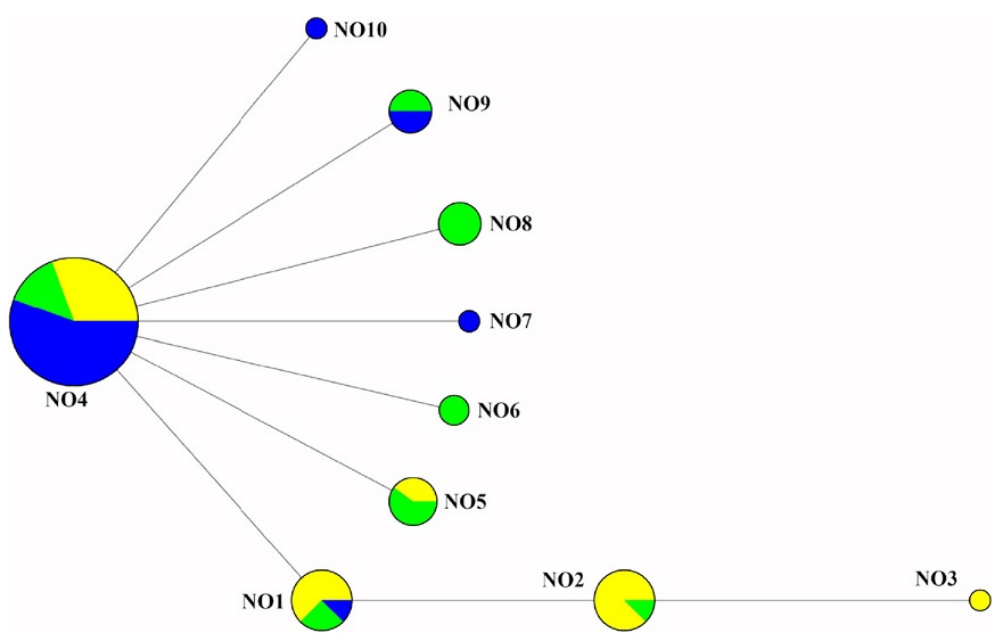

Figure 3 Haplotype network of ancient Norwegian haplotypes. Median-joining network of ancient Norwegian haplotypes showing their genetic relationship and frequency at different time periods.. Yellow: bottleneck period (c. 500-1,500 yr BP), green: pre-bottleneck period (c. 2,000-2,500 yr BP), blue: Mid-Holocene (c. 3,500-7,000 yr BP). Size of the circles is scaled according to the frequency of sequences. 
Table 2 Present mtDNA genetic structure and diversity of red deer for three geographic regions in Norway

\begin{tabular}{|c|c|c|c|c|c|c|c|c|c|c|c|}
\hline \multirow[b]{2}{*}{ Sample } & \multirow[b]{2}{*}{ \# seq. } & \multicolumn{3}{|c|}{ F-statistics } & \multicolumn{5}{|c|}{ Genetic diversity indices } & \multirow[b]{2}{*}{ D } & \multirow[b]{2}{*}{$F_{s}$} \\
\hline & & $\mathrm{N}$ & w & SW & $\mathrm{h}$ & $s$ & $\mathrm{H}_{\mathrm{d}}$ & $\pi$ & $\theta_{k}$ & & \\
\hline $\bar{N}$ & 86 & - & 0.658 & 0.816 & 4 & 4 & 0.213 & 0.0009 & 0.707 & -1.268 & -1.680 \\
\hline W & 45 & 0.507 & - & 0.204 & 4 & 4 & 0.643 & 0.0053 & 0.861 & 2.063 & 2.509 \\
\hline$\overline{S W}$ & 45 & 0.656 & 0.339 & - & 4 & 4 & 0.524 & 0.0019 & 0.861 & -0.763 & -0.427 \\
\hline Total & 176 & & & & 5 & 4 & 0.687 & 0.0051 & 0.821 & 2.537 & 2.979 \\
\hline
\end{tabular}

F-statistics: $\Phi_{S T}$ (above) and $F_{S T}$ (below). Genetic diversity indices: number of haplotypes (h) and segregating sites (s), haplotype diversity $\left(H_{d}\right)$, nucleotide diversity $(\pi)$, theta $\mathrm{k}\left(\theta_{\mathrm{k}}\right)$. Significant values of Tajima's $\mathrm{D}$ and Fu's $\mathrm{F}_{\mathrm{s}}$ in bold.

$\Phi_{\mathrm{ST}}=0.663, \mathrm{P}<0.001$; global $\left.\mathrm{F}_{\mathrm{ST}}=0.528, \mathrm{P}<0.001\right)$. Pair wise population differentiation was very high between regions and the most geographically distant populations were also the most genetically differentiated (Table 2). Overall haplotype diversity was moderate in the extant population while nucleotide diversity and $\theta_{\mathrm{k}}$ were low, both seemingly lowest in the northernmost area (Table 2). Among the Tajima's D or Fu's $F_{s}$ values only the D-value of the Sognefjord population (W) and the combined total genetic diversity of Norwegian deer differed significantly from equilibrium expectations, indicating a recent bottleneck.

\section{Genetic diversity through time in western Norway}

Considering only western Norway from where we have most of our ancient samples (70/73) it is clear that both the genetic diversity (Table 3 ) and the relative frequencies of haplotypes (Figure 3) have changed through time. The Early Iron Age samples (about 2,500-2,000 yr BP) show the highest diversity indices, while the number of haplotypes seems to have been reduced to the five types (NO1-NO5) found in the contemporary population already before the Middle Ages. Further loss of diversity is apparent when proceeding to the present as the once dominant haplotype NO4 has been lost in western Norway (W and SW areas) and is only found in the northern area in the present samples. $\theta_{\mathrm{k}}$-values are higher in all the ancient periods compared to the present (Table 3), indicating larger effective female population size in the past. None of the Tajima's D or Fu's $F_{s}$ values are significant except for the negative $F_{s}$ value of the mid-Holocene samples (in bold), which remains significant even after Bonferroni

Table 3 Genetic diversity through time in western Norway (W \& SW areas)

\begin{tabular}{lcccccccc}
\hline Sample & $\begin{array}{c}\# \\
\text { seq. }\end{array}$ & $\mathbf{h}$ & $\mathbf{s}$ & $\mathbf{H}_{\mathbf{d}}$ & $\boldsymbol{\pi}$ & $\boldsymbol{\theta}_{\mathbf{k}}$ & $\mathbf{D}$ & $\mathbf{F}_{\mathbf{s}}$ \\
\hline Present & 90 & 4 & 4 & 0.735 & 0.0040 & 0.699 & 1.368 & 2.335 \\
\hline Ancient total & 70 & 10 & 9 & 0.706 & 0.0034 & 2.962 & -1.091 & -3.756 \\
\hline c. 500-1500 yr BP & 26 & 5 & 4 & 0.732 & 0.0036 & 1.558 & 0.355 & -0.343 \\
\hline c. 2000-2500 yr BP & 19 & 7 & 6 & 0.971 & 0.0043 & 3.543 & -0.568 & -2.420 \\
\hline c. 3500-7000 yr BP & 25 & 5 & 4 & 0.363 & 0.0012 & 1.509 & -1.699 & $\mathbf{- 3 . 4 1 4}$ \\
\hline Notations as in Table 2. & & & & & & & &
\end{tabular}

correction, indicating population expansion. Among the five haplotypes found in the extant population all but NO3 have been found in samples older than any suspected translocation events.

\section{Bayesian skyline analysis}

The BSP suggest a relatively stable female effective population size, although with a wide confidence interval, until about 2,000 yr BP, when effective size starts to decrease in a stepwise manner (Figure 4). A Bayes factor of 106.8 indicates a strong support for the BSP model over the constant size model. The estimated substitution rate was $2.78 \times 10^{-7}(95 \%$ highest posterior density interval (HPDI): $\left.8.15 \times 10^{-8}-5.23 \times 10^{-7}\right)$ substitutions per site per year, which is in line with other studies using aDNA datasets $[66,67]$ and the rate estimated for red deer using only present European diversity [14].

\section{$A B C$ analyses}

Both in the direct and logistic approach, scenario 1 in Figure 2 has the highest support (Additional file 1: Figure S1), i.e. a single colonisation of Norway. The estimated type I and type II error rates are $13 \%$ and $21 \%$ respectively, implying a statistical power of $79 \%$. The estimated historical parameters based on scenario 1 are presented in Table 4. Median effective sizes of female Norwegian and European populations are $N_{\mathrm{NOR}}=7,160$ (95\% credible interval $1,870-32,000)$ and $N_{\mathrm{EUR}}=1.03$ mill (95\% CI 325,000 - 3.2 mill) and the European and Norwegian populations seemingly diverged from one another $t_{\mathrm{D}}=15,280(95 \%$ CI 9,960 - 19,560) years ago. There are only weak signs of bottleneck as modal values of $N_{\mathrm{B}}=10$ (95\% CI 1,110 - 85,700), but median value being $N_{\mathrm{B}}=22,700$, i.e., larger than the $N_{\mathrm{NOR}}$ estimate. The larger median value of $N_{\mathrm{B}}$ compared to $N_{\mathrm{NOR}}$ is likely an effect of assuming an equal population size before and after the bottleneck. The median time with varying population sizes is $t_{\mathrm{BS}}-t_{\mathrm{BE}}=976$ years $(95 \% \mathrm{CI}$ 452 - 1,704). All time estimates have relatively flat posterior probability distributions and estimates must be interpreted with caution. The bias (MRB) is low $(<1)$ for $N_{\text {NOR }}, N_{\text {EUR }}$ and $N_{\mathrm{B}}$ effective size estimates and the various time estimates, while moderate for estimated time 


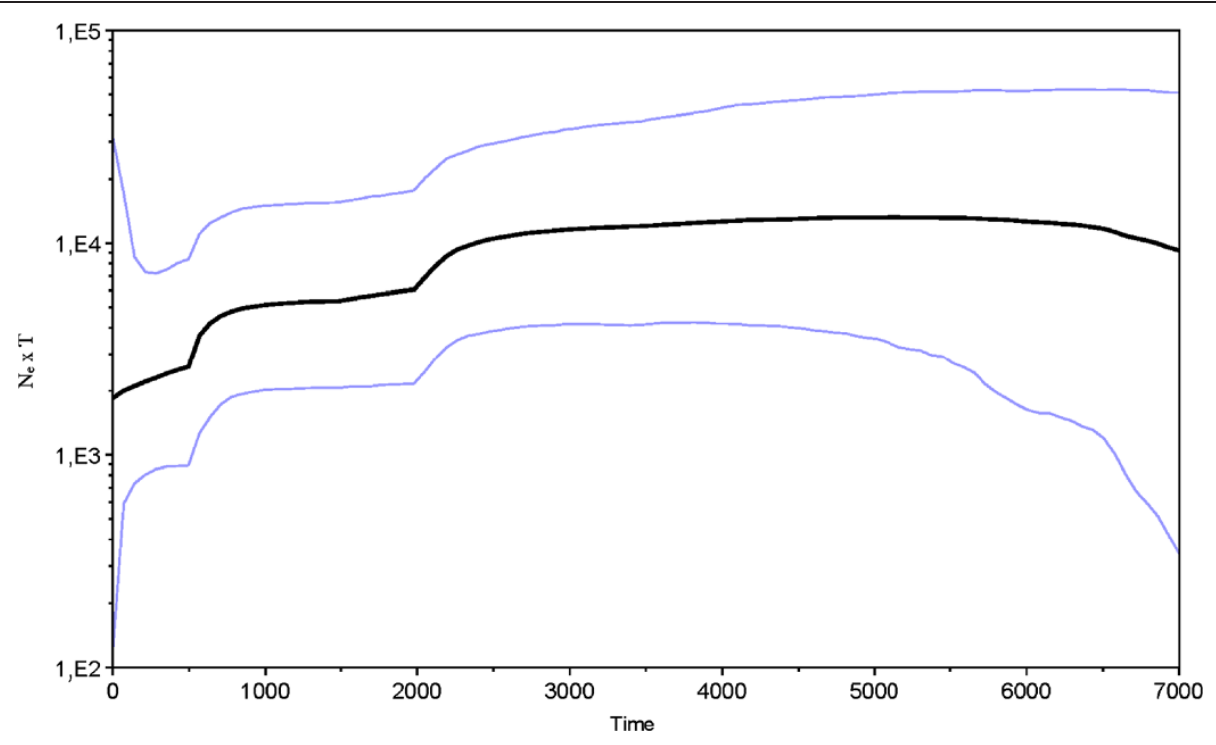

Figure 4 Effective female population size through time. Bayesian skyline plot (BSP) derived from the ancient and modern red deer dataset of western Norway. The $x$ axis is in calendar years before present and $y$ axis equals changes in effective population size (shown as the product of $\mathrm{N}_{\mathrm{e}}$ and generation time T). Black line is the median estimate and the blue lines show the $95 \%$ highest posterior density intervals.

with possible changes in effective sizes after divergence ( $x$, MRB equals 1.60) (Table 4).

The results from the simulations only using extant samples of DNA, and assuming scenario 1, are shown in parentheses in Table 4. The precision of the estimates are markedly reduced for some of the parameters causing MRB estimates to increase up to 6.8 times for various parameters when excluding aDNA samples compared to estimates including aDNA (average increase in MRB equal to 3.14 across all comparable parameters). However, the parameter estimates have partly overlapping credible intervals and in general the estimates are very similar, except that credible intervals on average is $20 \%$ larger in analyses excluding aDNA, i.e., including aDNA is seemingly increasing the precision of estimates.

\section{Placement in the western European lineage}

We sampled 131 sequences from the western European lineage which resulted in 83 haplotypes of the analysed fragment (Additional file 1: Table S2). The median-joining and statistical parsimony methods produced similar haplotype networks with the exception of an additional loop in the median-joining (Figure 5). The haplotypes cluster in star-like patterns around two central haplotypes identical to NO1 and NO4, with the central haplotype considered to be NO1 by the TCS program. This dual clustering is also apparent in the NeighborNet (Additional file 1: Figure S2). Five of the Norwegian haplotypes (NO1, NO4 - NO7) are shared with other countries while the other five have so far only been found in Norway.

Table 4 ABC historical parameter values

\begin{tabular}{|c|c|c|c|c|c|}
\hline Parameter & Median & Mode & $\mathrm{q}_{0.05}$ & $\mathrm{q}_{0.95}$ & MRB \\
\hline$N_{\mathrm{NOR}}$ & $7160(13700)$ & $3450(7910)$ & $1870(4590)$ & $32000(63700)$ & $0.11(0.11)$ \\
\hline$\overline{N_{E U R}}$ & $1030000(1000000)$ & $684000(639000)$ & $329000(325000)$ & 3200000 (2530000) & $0.21(0.17)$ \\
\hline$N_{B}$ & 22700 (34 100) & $10(4530)$ & $1110(2540)$ & 85700 (92 500) & $0.82(5.17)$ \\
\hline$x$ & $156(252)$ & $4(4)$ & $16(24)$ & $396(476)$ & $1.60(1.61)$ \\
\hline$t_{\mathrm{BE}}$ & $364(252)$ & $400(4)$ & $124(28)$ & $488(476)$ & $0.33(2.24)$ \\
\hline$t_{\mathrm{BS}}$ & $1340(1492)$ & $532(1360)$ & $576(600)$ & $2192(2408)$ & $0.17(0.18)$ \\
\hline$t_{D}$ & $15280(15000)$ & 19160 (18 520) & $9960(9760)$ & 19560 (19 560) & $0.01(0.05)$ \\
\hline$t_{1}$ & 1120 & 1268 & 560 & 1644 & 0.12 \\
\hline$t_{2}$ & 2292 & 2452 & 2032 & 2480 & $<0.01$ \\
\hline$t_{3}$ & 4840 & 3552 & 3608 & 6720 & 0.05 \\
\hline
\end{tabular}

Median, mode, quantiles and mean relative bias (MRB) for the posterior parameters calculated from scenario 1 including or excluding (in parentheses) ancient DNA as estimated from the ABC-analyses. 


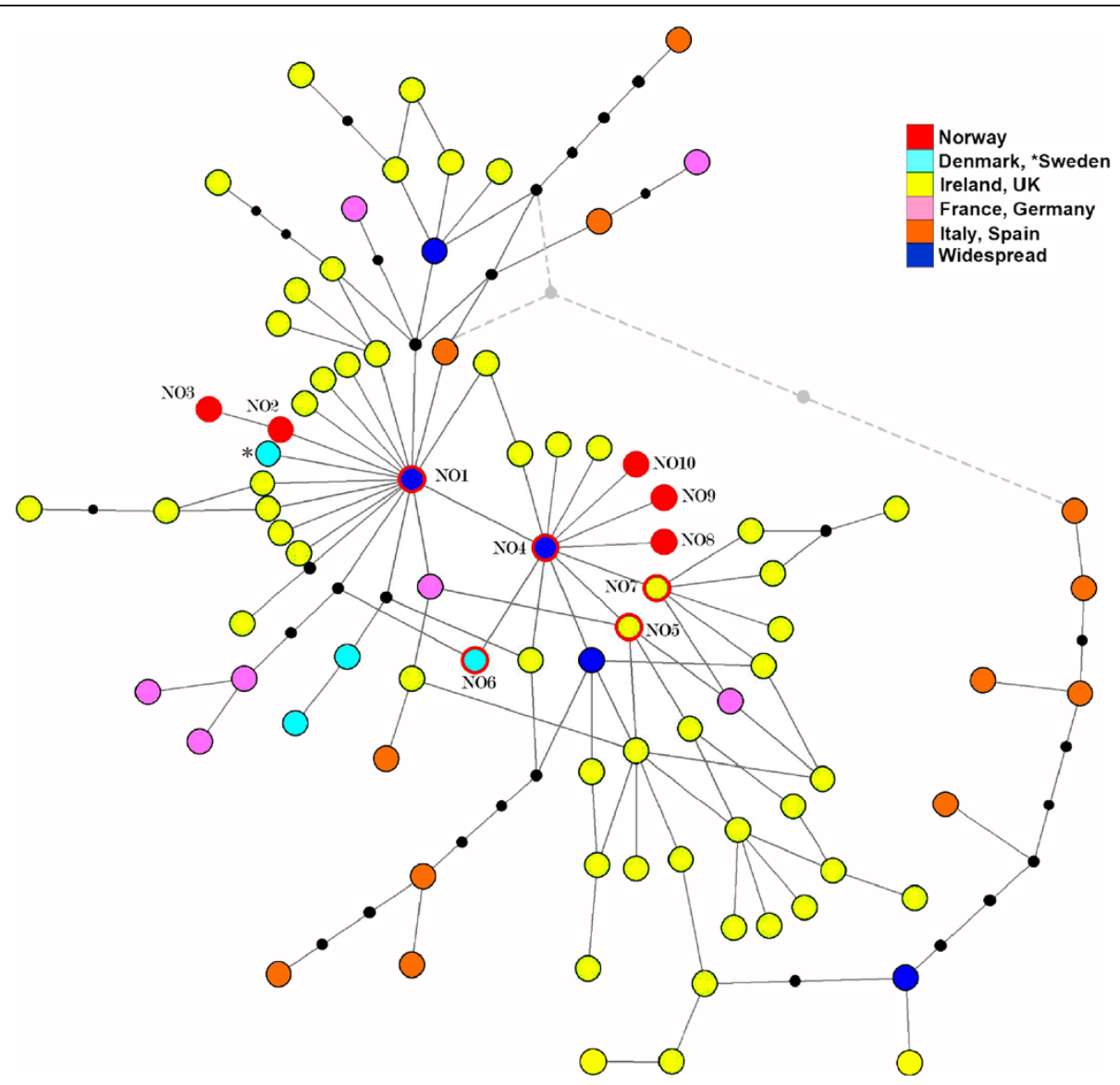

Figure 5 Relationships between western European red deer. Haplotype network of the western European lineage using both median-joining and statistical parsimony methods. Stapled line show connections only constructed when using the median-joining method. The branch lengths are not scaled to the number of substitutions and missing intermediate haplotypes are shown by black dots. Colour of circles and outlines indicates geographic location. Norwegian haplotypes are marked by named haplotypes. More info on haplotypes can be found in Additional file 1: Table S2.

\section{Discussion}

Red deer colonised western Norway some time before $8,000 \mathrm{yr}$ BP and skeletal remains indicate that they were well established by the start of the period covered by this analysis (Rosvold et al. unpublished results). While significant $F$ 's $F_{s}$ indicate a population expansion during the early part of our study period (Table 3), the BSP (Figure 4) suggests a relatively stable female effective population size until about 2,000 yr BP. However, as the samples for this early period are widely dispersed in time, the posterior density interval of the BSP is large and the estimate is thus insecure. The Early Iron Age sample (c. 2,500 - 2,000 yr BP) has the highest diversity indices of all periods considered (Table 3 ), indicating that the population size may have been particularly high during this time.

Historical texts tell of a widespread and large population in Norway until around $500 \mathrm{yr}$ BP, after which there was a dramatic decrease in numbers, allegedly caused by high harvesting rates and increased numbers of predators $[18,68]$. However, as indicated by the diversity indices, the BSP and the $\mathrm{ABC}$ analyses, this decrease appears to have been more prolonged, probably starting before medieval times. The estimated effective population sizes should be interpreted with caution $[69,70]$, but the relative changes give a reliable picture of the magnitude of the demographic bottleneck. Accordingly, and supported by an earlier study on contemporary microsatellite DNA [11], the bottleneck seems not to have been as dramatic as the historic texts may suggest. The mtDNA diversity in the present population is, however, relatively low (Table 2 ) and especially the nucleotide diversity is low compared to other European populations [71]. The lowest diversity estimates are found in the northernmost region $(\mathrm{N})$, as expected from a peripheral population loosing diversity during postglacial colonisation [72]. The current high population density of red deer in Norway is generally believed to be a recent 
phenomenon [17], but our results might indicate that at least the effective female population size, as measured through genetic diversity, was even higher in the past.

Following the spread of agriculture along the coast of western Norway the once dense coastal forests were transformed into the present day heathlands [73,74]. A process which was greatly accelerated from around 2,000 yr BP through intensified agricultural activities [75], iron, coal, and salt production, and later by mining and timber export [76]. These changes in the landscape probably facilitated and exacerbated the effects of heavy hunting by increasing habitat fragmentation and possibly reducing migration between areas, thereby isolating populations. The loss of the previously most abundant haplotype (NO4) may indicate extensive genetic drift within these fragmented populations, reducing genetic diversity on a local scale. However, the number of isolated populations were relatively large (at least six) and evenly spread along large parts of its former distribution [20]. Thus, the overall genetic diversity may have been better maintained by the wide geographic spread of the populations than if they had been reduced to a single but larger population [77]. Population fragmentation and isolation is expected to cause increased genetic differentiation [2], and indeed, there is a high degree of genetic structuring among the present Norwegian female red deer (Figure 1 and Table 2). This indicates that few females have migrated between the areas since the population size reduction, supporting findings that fjords may act as significant dispersal barriers [34,78].

The ten Norwegian haplotypes observed in the ancient samples are closely related to the rest of the western European clade. The star-like structuring (Figure 3) coupled with low nucleotide diversity (Table 3 ) is indicative of a population expansion from an ancestral haplotype [79] which in this case seems to be NO4. This close relationship, coupled with the observation that all present-day haplotypes except NO3 have been found in samples dating to 2,000 yr BP or older, is an indication of no human translocation of female red deer into Norway during historic times. This conclusion is also supported by $\mathrm{ABC}$ analyses, where a scenario of only one post-glacial colonisation of Norway gets highest support. NO3 is first found at low frequency in late medieval samples and has so far only been found in Norway (Figure 5). It is possible that NO3 originated in Norway and became frequent in the Sognefjord area (W, Figure 1) as an effect of genetic drift and subsequent population increase during recent times.

An estimated divergence time of the Norwegian population of around $15,000 \mathrm{yr}$ BP $(9,960-19,560)$, as indicated by the $\mathrm{ABC}$ analysis (Table 4), coincides with the start of the northward colonisation of Europe after the Last Glacial Maximum [9]. The haplotype network for the western European red deer (Figure 5) confirms previous findings of a close relationship within the western European clade [13,14], with little or no apparent geographic structure and several cross-links indicating uncertain relationships. Out of the ten haplotypes found in the ancient Norwegian dataset five are shared with other countries. Of these, the two central haplotypes NO1 and NO4 are widespread, being present in Scotland and the border forests between Germany and the Czech Republic $[14,23,25]$, with NO4 also found in Spain [14], and NO1 being one of the most common types found in the Scottish highlands today [25]. None of the extant Norwegian haplotypes are shared with other Scandinavian countries; although the ancient NO6 is found in Denmark today [27]. The Swedish population seems to have experienced a more severe bottleneck than the Norwegian as only one haplotype, closely related to NO1, is found among indigenous animals $[11,14]$. This low diversity makes it hard to postulate the relationship to Swedish animals, but present Scandinavian diversity indicates that some haplotypes never reached Norway and that a large part of those passing through Denmark during the postglacial colonization (i.e. the Norwegian types) were later lost. Sampling aDNA from both Sweden and Denmark could shed more light on if this was caused by genetic bottlenecks or if they were replaced by later immigrants that never reached Norway.

Two star shaped patterns are apparent among the western European samples, separated by an A-G transition. One of these centres on NO1, which has been described before [14], while the other centres on the closely related NO4 and is made more apparent by our ancient samples. This could be an indication of two subgroups within the western European haplogroup, possibly reflecting different refugial areas in France and Iberia [9]. Most of the European populations have undergone severe population reductions during recent centuries and several translocations which could have distorted any phylogeographic patterns within the haplogroup [6,71]. A large-scale sampling of aDNA from other European populations would thus provide valuable insights into the phylogeography of European red deer.

\section{Conclusions}

Our results indicate that the current genetic diversity of Norwegian red deer can be explained by one post-glacial immigration event followed by a gradual loss of diversity and increasing population sub-division due to heavy exploitation and habitat fragmentation during the last two millennia. They also show that only females from the western European red deer lineage colonised Scandinavia, supporting previous findings that the eastern lineage had a more limited dispersal into Europe $[14,80]$. The population decline seems to have been 
more prolonged in time than what is reflected in historic documents, indicating that even early human land use practices had an effect on red deer.

\section{Additional file}

Additional file 1: Additional file contains details of data collection and some aspects of data analyses. It also contains information on dating of ancient samples as well as an overview of the new sequences provided by this study. The file is in PDF format.

\section{Competing interests}

The authors declare that they have no competing interests.

\section{Authors' contributions}

$\mathrm{JR}$ did the laboratory work, analysed the data and drafted the manuscript. HKS performed the ABC-analyses. JR and AKH picked out the ancient samples. KHR supervised the laboratory work. All authors were involved in the study design, revising of the manuscript and read and approved the final manuscript.

\section{Acknowledgments}

We are very grateful to Hallvard Haanes and Anna Skog for providing additional info on the mtDNA diversity of the Norwegian red deer, and to Hallvard, John Linnell, Frank E. Zachos and an anonymous reviewer for valuable comments on the manuscript. We would also like to thank Liv Midthjell and Gro Bjørnstad for lab assistance, and Tore Fredriksen for help with providing samples. Funds were provided by the Directorate for Nature Management.

\section{Author details}

${ }^{1}$ Section of Natural History, Museum of Natural History and Archaeology, Norwegian University of Science and Technology, N-7491 Trondheim, Norway. ${ }^{2}$ Department of Basic Sciences and Aquatic Medicine, Norwegian School of Veterinary Science, Box 8146 Dep, N-0033 Oslo, Norway. ${ }^{3}$ The Natural History Collections, Bergen Museum, University of Bergen, Box 7800 5020 Bergen, Norway. ${ }^{4}$ The Norwegian Nature Inspectorate, Box 5672 , Sluppen, NO-7485 Trondheim, Norway.

Received: 31 May 2012 Accepted: 21 September 2012 Published: 26 September 2012

\section{References}

1. Frankham R, Ballou JD, Briscoe DA: Introduction to conservation genetics. Cambridge: Cambridge University Press; 2002.

2. Keyghobadi N: The genetic implications of habitat fragmentation for animals. Can J Zool 2007, 85:1049-1064.

3. Allendorf FW, England PR, Luikart G, Ritchie PA, Ryman N: Genetic effects of harvest on wild animal populations. Trends Ecol Evol 2008, 23:327-337.

4. Reed DH, Frankham R: Correlation between fitness and genetic diversity. Conserv Biol 2003, 17:230-237.

5. Garner A, Rachlow JL, Hicks JF: Patterns of genetic diversity and its loss in mammalian populations. Conserv Biol 2004, 19:1215-1221.

6. Linnell JDC, Zachos FE: Status and distribution patterns of European ungulates: genetics, population history and conservation. In Ungulate management in Europe: problems and practices. Edited by Putman $\mathrm{R}$, Apollonio M, Andersen R. Cambridge: Cambridge University Press; 2011:12-53.

7. Burbaité L, Csányi S: Red deer population and harvest changes in Europe. Acta Zool Lit 2010, 20:179-188.

8. Rhymer JM, Simberloff D: Extinction by hybridization and introgression. Annu Rev Ecol Syst 1996, 27:83-109.

9. Sommer RS, Zachos FE, Street M, Jöris O, Skog A, Benecke N: Late Quaternary distribution dynamics and phylogeography of the red deer (Cervus elaphus) in Europe. Quatern Sci Rev 2008, 27:714-733.

10. Gyllensten U, Ryman N, Reuterwall C, Dratch P: Genetic differentiation in four European subspecies of red deer (Cervus elaphus L.). Heredity 1983, 51:561-580.
11. Haanes $\mathrm{H}$, Røed KH, Perez-Espona S, Rosef O: Low genetic variation support bottlenecks in Scandinavian red deer. Eur J Wildl Res 2011 57:1137-1150

12. Lowe VPW, Gardiner AS: A re-examination of the subspecies of red deer (Cervus elaphus) with particular reference to the stocks in Britain. J Zool 1974, 174:185-201

13. Ludt CJ, Schroeder W, Rottmann O, Kuehn R: Mitochondrial DNA phylogeography of red deer (Cervus elaphus). Mol Phylogenet Evol 2004, 31:1064-1083

14. Skog A, Zachos FE, Rueness EK, Feulner PGD, Mysterud A, Langvatn R, Lorenzini R, Hmwe SS, Lehoczky I, Hartl GB, et al: Phylogeography of red deer (Cervus elaphus) in Europe. J Biogeogr 2009, 36:66-77.

15. Ahlén I: Studies on the red deer, Cervus elaphus L., in Scandinavia. II. Taxonomy and osteology of prehistoric and recent populations. Viltrevy 1965, 3:89-176.

16. Ekman S: Djurvärldens utbredningshistoria på Skandinaviska halvön Stockholm: Albert Bonniers Förlag; 1922.

17. Langvatn R: Hjortens erobring av Norge. In Brennpunkt Natur 98/99. Edited by Brox KH. Trondheim: Tapir; 1998:49-71.

18. Claussøn Friis P: Norriges oc omliggende øers sandfærdige bescriffuelse. Kjøbenhavn: Melkior Martzan; 1632.

19. Ahlén I: Studies on the red deer, Cervus elaphus L., in Scandinavia. I. History of distribution. Viltrevy 1965, 3:1-88

20. Collett R: Hjorten i Norge (Cervus elaphus, atlanticus), nogle biologiske meddelelser. Bergens Museums Aarbog 1909, 6:1-31.

21. Stuiver M, Reimer PJ: Extended C-14 data base and revised CALIB 3.0 C-14 age calibration program. Radiocarbon 1993, 35:215-230.

22. Reimer PJ, Baillie MGL, Bard E, Bayliss A, Beck JW, Bertrand CJH, Blackwell $P G$, Buck CE, Burr GS, Cutler KB, et al: IntCal04 terrestrial radiocarbon age calibration, 0-26 cal kyr BP. Radiocarbon 2004, 46:1029-1058.

23. Fickel J, Bubliy OA, Stache A, Noventa T, Jirsa A, Heurich M: Crossing the border? Structure of the red deer (Cervus elaphus) population from the Bavarian-Bohemian forest ecosystem. Mamm Biol 2012, 77:211-220.

24. McDevitt AD, Edwards CJ, O'Toole P, O'Sullivan P, O'Reilly C, Carden RF: Genetic structure of, and hybridisation between, red (Cervus elaphus) and sika (Cervus nippon) deer in Ireland. Mamm Biol 2009, 74:263-273.

25. Pérez-Espona S, Pérez-Barberia FJ, Goodall-Copestake WP, Jiggins CD, Gordon IJ: Genetic diversity and population structure of Scottish Highland red deer (Cervus elaphus) populations: a mitochondrial survey. Heredity 2009, 102:199-210.

26. Hmwe SS, Zachos FE, Sale JB, Rose HR, Hartl GB: Genetic variability and differentiation in red deer (Cervus elaphus) from Scotland and England. J Zool 2006, 270:479-487.

27. Nielsen EK, Olesen CR, Pertoldi C, Gravlund P, Barker JSF, Mucci N, Randi E, Loeschcke V: Genetic structure of the Danish red deer (Cervus elaphus). Biol J Linn Soc 2008, 95:688-701.

28. Randi E, Mucci N, Claro-Hergueta F, Bonnet A, Douzery EJP: A mitochondrial DNA control region phylogeny of the Cervinae: speciation in Cervus and implications for conservation. Anim Conserv 2001, $4: 1-11$.

29. Haanes H, Røed KH, Mysterud A, Langvatn L, Rosef O: Consequences for genetic diversity and population performance of introducing continental red deer into the northern distribution range. Conserv Genet 2010, 11:1653-1665.

30. Tamura K, Dudley J, Nei M, Kumar S: MEGA4: Molecular evolutionary genetics analysis (MEGA) software version 4.0. Mol Biol Evol 2007, 24:1596-1599.

31. Cooper A, Poinar HN: Ancient DNA: do it right or not at all. Science 2000 289:1139.

32. den Tex R-J, Maldonado JE, Thorington R, Leonard JA: Nuclear copies of mitochondrial genes: another problem for ancient DNA. Genetica 2010, 138:979-984.

33. Haanes $\mathrm{H}$, Røed KH, Flagstad Ø, Rosef O: Genetic structure in an expanding cervid population after population reduction. Conserv Genet 2010, 11:11-20.

34. Wright S: The genetical structure of populations. Ann Eugenics 1951, 15:323-354.

35. Excoffier L, Smouse PE, Quattro JM: Analysis of molecular variance inferred from metric distances among DNA haplotypes: application to human mitochondrial DNA restriction data. Genetics 1992,

131:479-491. 
36. Excoffier L, Laval G, Schneider S: Arlequin (version 3.0): An integrated software package for population genetics data analysis. Evol Bioinform 2005, 1:47-50.

37. Navascués M, Emerson BC: Elevated substitution rate estimates from ancient DNA: model violation and bias of Bayesian methods. Mol Ecol 2009, 18:4390-4397.

38. Ho SYW, Shapiro B: Skyline-plot methods for estimating demographic history from nucleotide sequences. Mol Ecol Resour 2011, 11:423-434.

39. Pannell JR: Coalescence in a metapopulation with recurrent local extinction and recolonization. Evolution 2003, 57:949-961.

40. Ewens WJ: The sampling theory of selectively neutral alleles. Theor Popul Biol 1972, 3:87-112.

41. Tajima F: Statistical method for testing the neutral mutation hypothesis by DNA polymorphism. Genetics 1989, 123:585-595.

42. Fu YX: Statistical tests of neutrality of mutations against population growth, hitchhiking and background selection. Genetics 1997, 147:915-925.

43. Drummond AJ, Rambaut A, Shapiro B, Pybus OG: Bayesian coalescent inference of past population dynamics from molecular sequences. Mol Biol Evol 2005, 22:1185-1192.

44. Drummond A, Rambaut A: BEAST: Bayesian evolutionary analysis by sampling trees. BMC Evol Biol 2007, 7:214.

45. Drummond AJ, Nicholls GK, Rodrigo AG, Solomon W: Estimating mutation parameters, population history and genealogy simultaneously from temporally spaced sequence data. Genetics 2002, 161:1307-1320.

46. Guindon S, Gascuel O: A simple, fast, and accurate algorithm to estimate large phylogenies by maximum likelihood. Syst Biol 2003, 52:696-704.

47. Posada D: jModelTest: phylogenetic model averaging. Mol Biol Evol 2008, 25:1253-1256

48. Hasegawa M, Kishino H, Yano T-a: Dating of the human-ape splitting by a molecular clock of mitochondrial DNA. J Mol Evol 1985, 22:160-174.

49. Tracer v1.4. http://beast.bio.ed.ac.uk/Tracer.

50. Suchard MA, Weiss RE, Sinsheimer JS: Bayesian selection of continuoustime Markov Chain evolutionary models. Mol Biol Evol 2001, 18:1001-1013.

51. Beaumont MA, Zhang W, Balding DJ: Approximate Bayesian computation in population genetics. Genetics 2002, 162:2025-2035.

52. Cornuet J-M, Santos F, Beaumont MA, Robert CP, Marin J-M, Balding DJ, Guillemaud T, Estoup A: Inferring population history with DIY ABC: a userfriendly approach to approximate Bayesian computation. Bioinformatics 2008, 24:2713-2719.

53. Städler T, Haubold B, Merino C, Stephan W, Pfaffelhuber P: The impact of sampling schemes on the site frequency spectrum in nonequilibrium subdivided populations. Genetics 2009, 182:205-216

54. Stenøien HK, Shaw AJ, Shaw B, Hassel K, Gunnarsson U: North American origin and recent European establishments of the amphi-Atlantic peat moss Sphagnum angermanicum. Evolution 2011, 65:1181-1194.

55. Kimura M: A simple method for estimating evolutionary rates of base substitutions through comparative studies of nucleotide sequences. J Mol Evol 1980, 16:111-120.

56. Miller N, Estoup A, Toepfer S, Bourguet D, Lapchin L, Derridj S, Kim KS, Reynaud P, Furlan L, Guillemaud T: Multiple transatlantic introductions of the western corn rootworm. Science 2005, 310:992.

57. Pascual M, Chapuis MP, Mestres F, BalanyÀ J, Huey RB, Gilchrist GW, Serra L, Estoup A: Introduction history of Drosophila subobscura in the New World: a microsatellite-based survey using ABC methods. Mol Ecol 2007, 16:3069-3083.

58. Fagundes NJR, Ray N, Beaumont M, Neuenschwander S, Salzano FM, Bonatto SL, Excoffier L: Statistical evaluation of alternative models of human evolution. Proc Natl Acad Sci USA 2007, 104:17614-17619.

59. Beaumont MA: Joint determination of topology, divergence time, and immigration in population trees. In Simulations, genetics and human prehistory. Edited by Matsura S, Forster P, Renfrew C. Cambridge: McDonald Institute for Archaeological Research; 2008:135-154.

60. Bandelt HJ, Forster P, Röhl A: Median-joining networks for inferring intraspecific phylogenies. Mol Biol Evol 1999, 16:37-48.

61. Clement M, Posada D, Crandall KA: TCS: a computer program to estimate gene genealogies. Mol Ecol 2000, 9:1657-1659.

62. Huson DH, Bryant D: Application of phylogenetic networks in evolutionary studies. Mol Biol Evol 2006, 23:254-267.

63. Zhang Z, Schwartz S, Wagner L, Miller W: A greedy algorithm for aligning DNA sequences. J Comput Biol 2000, 7:203-214.
64. Leonard JA, Shanks O, Hofreiter M, Kreuz E, Hodges L, Ream W, Wayne RK, Fleischer RC: Animal DNA in PCR reagents plagues ancient DNA research. J Archaeol Sci 2007, 34:1361-1366

65. Gilbert MTP, Binladen J, Miller W, Wiuf C, Willerslev E, Poinar H, Carlson JE, Leebens-Mack JH, Schuster SC: Recharacterization of ancient DNA miscoding lesions: insights in the era of sequencing-by-synthesis Nucleic Acids Res 2007, 10:1-10.

66. Baker K: Population genetic history of the British roe deer (Capreolus capreolus) and its implications for diversity and fitness. PhD thesis: Durham University, School of Biological and Biomedical Sciences; 2011

67. Ho SYW, Lanfear R, Phillips MJ, Barnes I, Thomas JA, Kolokotronis S-O, Shapiro B: Bayesian estimation of substitution rates from ancient DNA sequences with low information content. Syst Biol 2011, 60:366-375.

68. Pontoppidan E: Norges naturlige historie: 1752-1753. København: Rosenkilde og Bagger; 1753. Facsimile edition (1977).

69. Bazin E, Glémin S, Galtier N: Population size does not influence mitochondrial genetic diversity in animals. Science 2006, 312:570-572

70. Nabholz B, Glémin S, Galtier N: The erratic mitochondrial clock: variations of mutation rate, not population size, affect mtDNA diversity across birds and mammals. BMC Evol Biol 2009, 9:54.

71. Zachos FE, Hartl GB: Phylogeography, population genetics and conservation of the European red deer Cervus elaphus. Mamm Rev 2011, 41:138-150.

72. Eckert CG, Samis KE, Lougheed SC: Genetic variation across species' geographical ranges: the central-marginal hypothesis and beyond. Mol Ecol 2008, 17:1170-1188.

73. Kaland PE: The origin and management of Norwegian coastal heaths as reflected by pollen analysis. In Anthropogenic indicators in pollen diagrams. Edited by Fasteland A. Rotterdam: A.A.Balkema; 1986:19-36.

74. Høgestø| M, Prøsch-Danielsen L: Impulses from agro-pastoralism in the 4th and 3rd millennia BC on the south-western coastal rim of Norway. Environ Archaeol 2006, 11:19-34.

75. Myhre B: Agriculture, landscape and society ca. 4000 BC - AD 800. In Norwegian agricultural history. Edited by Gjerdåker B, Lunden K, Myhre B, Øye I. Trondheim: Tapir Academic Press; 2004:12-77.

76. Rolstad J, Framstad E, Gundersen V, Storaunet KO: Naturskog i Norge. Definisjoner, økologi og bruk i norsk skog- og miljøforvaltning. Aktuelt fra skogforskningen 2001, 1:1-53.

77. Lacy RC: Loss of genetic diversity from managed populations: interacting effects of drift, mutation, immigration, selection, and population subdivision. Conserv Biol 1987, 1:143-158.

78. Pérez-Espona S, Pérez-Barberia FJ, McLeod JE, Jiggins CD, Gordon IJ, Pemberton JM: Landscape features affect gene flow of Scottish Highland red deer (Cervus elaphus). Mol Ecol 2008, 17:981-996.

79. Richards M, Macaulay V, Hickey E, Vega E, Sykes B, Guida V, Rengo C, Sellitto D, Cruciani F, Kivisild T, et al: Tracing European founder lineages in the near eastern mtDNA pool. Am J Hum Genet 2000, 67:1251-1276.

80. Niedzialkowska M, Jedrzejewska B, Honnen A-C, Otto T, Sidorovich VE, Perzanowski K, Skog A, Hartl GB, Borowik T, Bunevich AN, et al: Molecular biogeography of red deer Cervus elaphus from eastern Europe: insights from mitochondrial DNA sequences. Acta Therio/ 2011, 56:1-12.

\section{doi:10.1186/1471-2148-12-191}

Cite this article as: Rosvold et al:: Reconstructing the history of a fragmented and heavily exploited red deer population using ancient and contemporary DNA. BMC Evolutionary Biology 2012 12:191. 